Simulation of shear-type cracking and failure with non-linear finite-element method

H. Broo, M. Plos, K. Lundgren and B. Engström

Published in Magazine of Concrete Research, see journal homepage http://www.icevirtuallibrary.com/content/journals

"Permission is granted by ICE Publishing to print one copy for personal use. Any other use of these PDF files is subject to reprint fees." 


\title{
Simulation of shear-type cracking and failure with non-linear finite-element method
}

\author{
H. Broo, M. Plos, K. Lundgren and B. Engström \\ Chalmers University of Technology
}

\begin{abstract}
Today, the non-linear finite-element (FE) method is commonly used by practising engineers. Simulating the shear behaviour and shear failure of reinforced concrete structures, using three-dimensional non-linear finite-element methods, has shown higher load-carrying capacity due to favourable load distribution, compared to conventional analyses. However, the modelling method for reinforced and prestressed concrete members subjected to shear and torsion has not been generally verified. Therefore, the method needs to be investigated further and confirmed to be practically reliable. The aim of this project is to develop, improve and verify a method to simulate the shear response of reinforced and prestressed concrete members. The method should be applicable for large structures, for example box-girder bridges, subjected to various load actions. Experiments with panels loaded in shear and beams loaded in bending, shear and torsion are simulated by using non-linear FE analysis. The results showed that fournode curved shell elements with embedded reinforcement could simulate the shear response. It is well known that the shear sliding capacity is larger than that which can be explained by the reinforcement contribution determined from a truss model. This increase is due to dowel action and aggregate interlock, and has been accounted for in the past by modifying the concrete tension response in models - for example, according to the modified compression field theory (MCFT). Results from the analyses show that without any modification, the capacity was underestimated and the average strains-that is, the crack widths-were overestimated. On the other hand, if the concrete contribution to the shear capacity was considered with the expression from MCFT, the capacity was in many cases overestimated and the average strains underestimated.
\end{abstract}

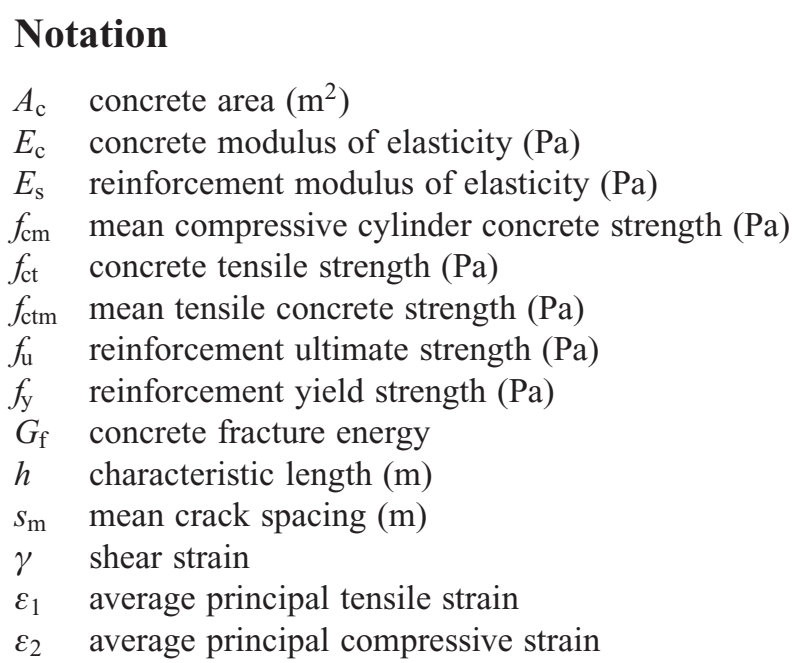

Department of Civil and Environmental Engineering, Structural Engineering, Concrete Structures, Chalmers University of Technology, SE-412 96 Göteborg, Sweden

(MCR 700012) Paper received 11 January 2007; last revised 25 April 2007; accepted 4 June 2007

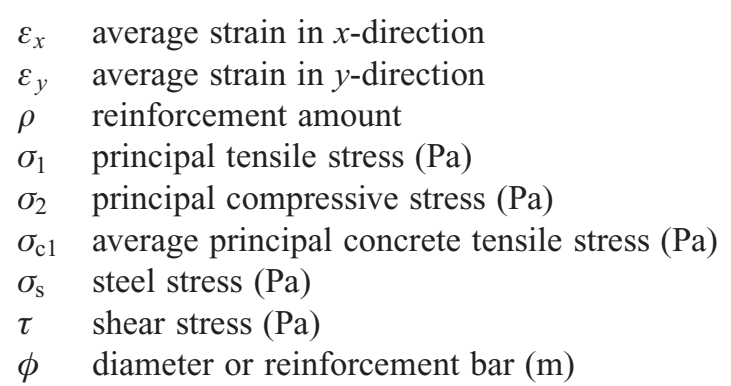

\section{Introduction}

For structural design and assessment of reinforced concrete (RC) members, the non-linear finite-element (FE) analysis has become an important tool. However, design and assessment for shear and torsion are still made today with simplified analytical or empirical design methods. In some cases, more enhanced methods are used, such as the modified compression field theory (MCFT) of Vecchio and Collins. ${ }^{1}$ These methods all use sectional forces and moments, which usually are determined through elastic beam or frame analysis or 
linear FE analysis. The current calculation method for $\mathrm{RC}$ members subjected to combined shear and torsion, in the European Standard EC2 CEN/TC250/SC2, ${ }^{2}$ adds stresses from shear and from torsion linearly without taking into account deformations and compatibility within the member. However, earlier research indicates that there is a redistribution within concrete members lacking transverse reinforcement, ${ }^{3,4}$ and that this could be modelled with non-linear FE analyses. ${ }^{5,6}$ It is also well known that the shear capacity is larger than what can be explained by the reinforcement contribution determined from a truss model. Non-linear FE analyses of concrete members with transverse reinforcement subjected to shear have been reported by several researchers, for example Ayoub and Filippou, ${ }^{7}$ Yamamoto and Vecchio, ${ }^{8}$ Vecchio and Shim ${ }^{9}$ and Kettil et al. ${ }^{10}$ In recently conducted research projects, failures owing to shear and torsion were successfully simulated with nonlinear FE analyses, also for members with transverse reinforcement (see $\mathrm{Plos}^{11}$ ). A higher load-carrying capacity compared with conventional analysis was shown. This can be explained by a more favourable load distribution, when the structure has been analysed in three dimensions and by including the fracture energy associated with concrete cracking. Here, though, the modelling method used for reinforced and prestressed concrete members subjected to shear and torsion had not been verified. The modelling method therefore requires further study and verification in order to be reliable and practically applicable.

The aim of this project is to develop a method to model and simulate shear-type cracking and shear failure of reinforced and prestressed concrete members. It should be possible to use the method for analyses of more complex structures, for example box-girder bridges, subjected to bending, shear, torsion and combinations of these load actions. Engineers using commercial non-linear FE programs, not specially designed for shear analysis, should be able to use the method in their daily practice. Further aims are to examine and determine the most important parameters that need to be accounted for in the material model or in the material properties used. The mechanisms contributing to the shear resistance of cracked concrete are explained and various ways to model these are briefly presented. Tests of panels loaded in shear and beams loaded in bending, shear and torsion are simulated by using the non-linear finite-element method (FEM) and the results are compared.

\section{The non-linear response in shear}

Both shear forces and torsional moments cause shear stresses that can result in cracks in a concrete member. Cracks owing to shear stresses are usually inclined relative to the direction of the reinforcement. To satisfy the new equilibrium after shear cracking, longitudinal reinforcement and transverse reinforcement or friction in the crack is required. After cracking, the shear force is transmitted by compression in the concrete between the inclined cracks, tension in the transverse reinforcement crossing the inclined cracks, tension in the longitudinal reinforcement, compression and shear in the compressive zone and stresses transferred over the crack, for example through aggregate interlocking along the crack. The visual shear cracks are preceded by the formation of micro-cracks. The micro-cracking and the following crack formation change the stiffness relations in the member, and a redistribution of stresses can occur resulting in strut inclinations smaller than $45^{\circ}$ (see Hegger et $a l .{ }^{12}$ ). Owing to the rotation of the struts, more transverse reinforcement can be activated. This behaviour becomes more pronounced when the transverse reinforcement starts to yield. The rotation of the compressive struts can continue until failure. Possible failure modes in shear are: (a) sliding along a shear crack; (b) crushing of the concrete between two shear cracks; or (c) crushing of the concrete in the compressive zone. In the case of transverse reinforcement, shear sliding cannot take place before the transverse reinforcement yields. It is well known that the shear capacity is larger than what can be explained by the reinforcement contribution determined from a truss model. This increase in shear capacity is caused by tension stiffening, compression and shear in the compressive zone and stresses transferred over the crack, for example tension softening, dowel action and aggregate interlocking. This increase is also known as the concrete contribution'.

After cracking, concrete can transmit tensile stresses owing to tension softening, and for $\mathrm{RC}$ also owing to tension stiffening. Tension softening is the capability of plain concrete to transfer tensile stresses after crack initiation. In an RC member subjected to tensile forces, tensile stresses are transferred by bond from the reinforcement to the concrete in between the cracks, which contributes to the stiffness of the member. This is known as the tension stiffening. The tension stiffening effect increases the overall stiffness of the RC member in tension compared with that of the bare reinforcement. Owing to both tension stiffening and tension softening, there are still significant transverse tensile stresses in the compressive struts. Cracked concrete subjected to tensile strains in the direction transverse to the compression is softer and weaker in compression than concrete in a standard cylinder test. ${ }^{1,13,14}$

The complex behaviour of RC after shear crack initiation has been explained in several papers (see for example References 1 and 15-20). The equilibrium conditions can be expressed in average stresses for a region containing several cracks, or in local stresses at a crack. The local stresses normal to the crack plane are carried by the reinforcement and by the bridging stresses of plain concrete (tension softening). Along the crack plane, the shear stresses are carried by aggregate 
interlocking and dowel action. The stresses will depend on the shear slip, the crack width, the concrete composition (strength, grading curve and maximum aggregate size) and of course the reinforcement (type, diameter and spacing). ${ }^{21}$

\section{Modelling of the non-linear shear behaviour}

Several analytical models that are capable of predicting the non-linear response in shear have been presented, for example the MCFT of Vecchio and Collins, ${ }^{1}$ the distributed stress field model (DSFM) of Vecchio, ${ }^{22}$ the cracked membrane model (CMM) of Kaufmann and Marti, ${ }^{23}$ the rotating-angle softened truss model (RA-STM) of Pang and Hsu, ${ }^{16}$ the fixed-angle softened truss model (FA-STM) of Pang and $\mathrm{Hsu}^{24}$ and the softened membrane model (SMM) of Hsu and Zhu. ${ }^{25}$ All these models are based on the smeared crack approach - that is, the influences of cracks are smeared over a region and the calculations are made with average stresses and average strains. Stress equilibrium, strain compatibility and constitutive laws are used to predict the shear force for chosen strains. Some models use a rotating crack concept and thus no relationship between shear stress and shear strain is needed for the concrete. Others are based on a fixed crack concept including a relationship for average shear stresses and average shear strains. Most of the models are also implemented in FE programs. Soltani et al. ${ }^{20}$ propose a model based on formulations of local stresses and strains at the crack plane, separating the contributions from tension softening, tension stiffening, aggregate interlocking and dowel action, to predict the non-linear shear response.

If the shear-type cracking and shear failure are modelled and simulated with the non-linear FEM, with an FE program not specially designed for shear analysis, parts of the concrete contribution need to be accounted for by modifying the constitutive relationships used. The modifications needed depend on the modelling method, material model, and how the interaction between reinforcement and concrete is modelled.

Modelling of reinforcement and the interaction between reinforcement and concrete can be made more or less detailed. When modelling larger structures - that is, box-girder bridges - a simple approach is needed and the reinforcement can be modelled as embedded in the concrete elements. Embedded reinforcement can be applied to any type of FE that represents the concrete. The embedded reinforcement adds stiffness to the FE representing the concrete, but the reinforcement has no degree of freedom of its own. Hence, the reinforcement is perfectly bonded to the surrounding concrete and no slip can occur. In this case the effects of the concrete contribution, described above, must be taken into account in the constitutive relations describing the materi- als' behaviour, for example the concrete in tensile response or in the reinforcement response. Ways of doing this for the tension stiffening have been proposed by Kaufmann and Marti $^{23}$ and Lackner and Mang. ${ }^{26}$ Relationships between tensile stress and crack opening in plain concrete are based on fracture mechanics and related to the fracture energy, $G_{\mathrm{f}}$; an example is the relation proposed by Hordijk, as described in Reference 27. For RC members subjected to shear, the contribution from dowel action and aggregate interlocking can also be accounted for in the constitutive relations. Such relationships that link the average tensile stress to the average tensile strain for orthogonally reinforced concrete have been established on the basis of shear panel tests. Vecchio and Collins ${ }^{1}$ suggested

$$
\sigma_{\mathrm{c} 1}=\frac{f_{\mathrm{ctm}}}{1+\sqrt{200 \varepsilon_{1}}}
$$

after several tests on thin panels reinforced with smooth welded wire meshes with close spacing-the 'Toronto panels'. Here $\sigma_{\mathrm{c} 1}$ is the average principal tensile stress, $f_{\text {ctm }}$ is the mean tensile concrete strength and $\varepsilon_{1}$ is the average principal tensile strain. Following tests on thicker panels reinforced with coarser reinforcement this was changed to

$$
\sigma_{\mathrm{c} 1}=\frac{f_{\mathrm{ctm}}}{1+\sqrt{500 \varepsilon_{1}}}
$$

which is the relationship used in the MCFT of Collins and Mitchell. ${ }^{28}$ Bentz $^{29}$ compared these relationships with

$$
\sigma_{\mathrm{c} 1}=f_{\mathrm{ctm}}\left(\frac{0 \cdot 00008}{\varepsilon_{1}}\right)^{4}
$$

which was suggested for the softened truss model of Pang and Hsu, ${ }^{16}$ and evaluated from tests on thick panels reinforced with widely spaced coarse bar reinforcement. In Fig. 1 the relationships by Vecchio and Collins, ${ }^{1}$ Pang and $\mathrm{Hsu}^{16}$ and Hordijk ${ }^{27}$ are compared for one particular shear panel. By adjusting the expression by Vecchio and Collins ${ }^{1}$ to depend on reinforcement ratio and rebar diameter, Bentz ${ }^{29}$ proposed

$$
\sigma_{\mathrm{c} 1}=\frac{f_{\mathrm{ctm}}}{1+\sqrt{3 \cdot 6 M \varepsilon_{1}}}
$$

where

$$
M=\frac{A_{\mathrm{c}}}{\sum \phi \pi}
$$

Here $A_{\mathrm{c}}$ is the concrete area and $\phi$ is the diameter of the reinforcement bar. These relationships should be limited so that no concrete tensile stress is transmitted after the reinforcement has started to yield. This is a problem when modifying the relationship for concrete in tension in an FE program, since there is no obvious link between the steel strain in the reinforcement direction and the concrete strain in the 


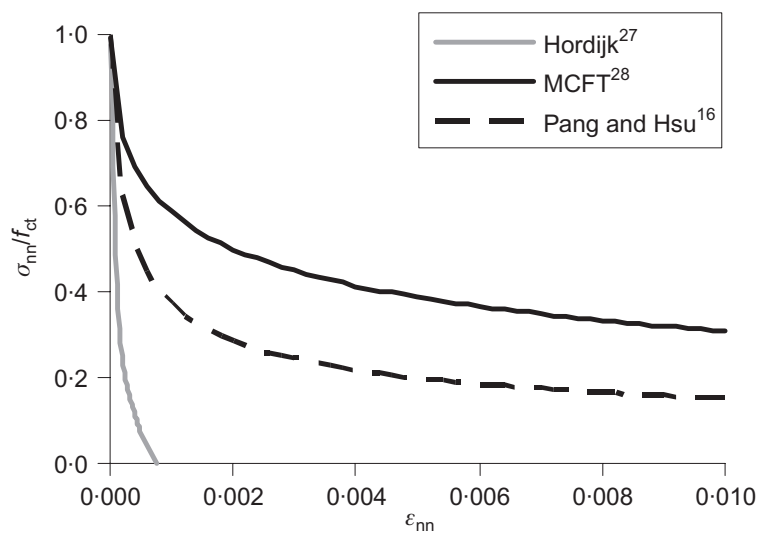

Fig. 1. Different tension-softening relations compared for Houston panel A3. For the curve by Hordijk the fracture energy is smeared over a length of $150 \mathrm{~mm}$ (the crack band width, $h$ ), which corresponds to the calculated average crack spacing

principal stress direction. Hence, the cracked concrete can transfer tensile stresses in the principal stress direction even when the reinforcement in any direction yields.

The relationships by Vecchio and Collins, ${ }^{1}$ Collins and Mitchell, ${ }^{28}$ Pang and $\mathrm{Hsu}^{16}$ and Bentz ${ }^{29}$ were established for analysis of orthogonally reinforced concrete panels subjected to shear. However, more general applicability for members with deviating reinforcement or specimens subjected to, for instance, bending or tension is not shown and is rather doubtful. In the following analyses, the use of the tension-softening curve by Hordijk and a curve modified according to MCFT are compared for several RC members.

\section{Modelling technique}

The non-linear FE program DIANA and the following modelling approach were used to simulate tests of $\mathrm{RC}$ and prestressed concrete members subjected to bending, shear, torsion or combinations of these. This included tests on shear panels, the 'Toronto panels' of Vecchio and Collins ${ }^{1}$ and the 'Houston panels' of Pang and $\mathrm{Hsu},{ }^{16}$ and beams with various cross-sections and various load actions according to Karlsson and Elfgren $^{30}$ and Magnusson. ${ }^{31}$

In all analyses the concrete was modelled with fournode curved shell elements. For the specimens modelled here, plane-stress elements would have been more appropriate to use, but the aim was to develop an analysis method that could be used also for more complex structures, for which curved shell elements are more suitable. Full interaction was assumed between the reinforcement and the concrete. The concrete was modelled with a constitutive model based on non-linear fracture mechanics. In most of the analyses a rotating crack model based on total strain ${ }^{27}$ was used. For some of the analyses this was compared with the use of a fixed crack model. ${ }^{27}$ For most analyses the hardening of concrete in compression was described by the expression of Thorenfeldt and the reduction of the strength owing to transverse tensile strains was modelled according to Vecchio and Collins, as described in TNO ${ }^{27}$ when something else is used, this is specifically pointed out. For the tension softening, two approaches were compared

(a) the curve by Hordijk, ${ }^{27}$ where only the fracture energy of plain concrete is taken into account

(b) a curve modified according to the expression from the MCFT of Collins and Mitchell, ${ }^{28}$ which attempts to take into account also the concrete contribution when subjected to shear, see Fig. 1. For the curve by Hordijk, the fracture energy is smeared over a length, $h$, the crack band width, which corresponds to the mean crack spacing obtained in the test or calculated according to Collins and Mitchell. ${ }^{28}$

The concrete material properties used in all analyses are presented in Table 1. The concrete tensile strength, $f_{\mathrm{ct}}$, the concrete modulus of elasticity, $E_{\mathrm{c}}$, and the fracture energy $G_{\mathrm{f}}$ were calculated according to fib ${ }^{21}$ from the mean cylinder compressive strength, $f_{\mathrm{cm}}$, reported from the tests. The constitutive relations of the reinforcement and the prestressing steel were modelled by the von Mises yield criterion with an associated flow law

Table 1. Material properties for concrete used in the analyses of the Toronto panel tests, the Houston panel tests and the beam tests

\begin{tabular}{l|l|c|c|c|c|c|c}
\hline \multicolumn{2}{l|}{} & $f_{\mathrm{cm}}: \mathrm{MPa}$ & $f_{\mathrm{ctm}}: \mathrm{MPa}$ & $E_{\mathrm{c}}: \mathrm{GPa}$ & $G_{\mathrm{f}}: \mathrm{Nm} / \mathrm{m}^{2}$ & \multicolumn{1}{|c|}{$s_{\mathrm{m}}: \mathrm{mm}$} & $h: \mathrm{m}$ \\
\hline Teronto panel & PV10 & $14 \cdot 5$ & $1 \cdot 04$ & $24 \cdot 30$ & $32 \cdot 4$ & $50 \cdot 0$ & $0 \cdot 050$ \\
& PV19 & $19 \cdot 0$ & $1 \cdot 48$ & $26 \cdot 60$ & $39 \cdot 2$ & $50 \cdot 0$ & $0 \cdot 050$ \\
& PV20 & $19 \cdot 6$ & $1 \cdot 58$ & $26 \cdot 90$ & $44 \cdot 0$ & $50 \cdot 0$ & $0 \cdot 050$ \\
Houston panel & A3 & $41 \cdot 6$ & $3 \cdot 12$ & $34 \cdot 58$ & $67 \cdot 8$ & $151 \cdot 2$ & $0 \cdot 150$ \\
& B1 & $45 \cdot 2$ & $3 \cdot 34$ & $35 \cdot 55$ & $71 \cdot 9$ & $194 \cdot 7$ & $0 \cdot 195$ \\
& B2 & $44 \cdot 0$ & $3 \cdot 27$ & $35 \cdot 24$ & $70 \cdot 6$ & $163 \cdot 7$ & $0 \cdot 165$ \\
& B4 & $44 \cdot 7$ & $3 \cdot 31$ & $35 \cdot 42$ & $71 \cdot 3$ & $173 \cdot 2$ & $0 \cdot 175$ \\
Beams & Beam 5 & $24 \cdot 9$ & $1 \cdot 97$ & $29 \cdot 14$ & $47 \cdot 3$ & & \\
& NSC 3 & $27 \cdot 3$ & $2 \cdot 16$ & $30 \cdot 05$ & $88 \cdot 9$ & $107 \cdot 0$ & $0 \cdot 107$ \\
\hline
\end{tabular}


and isotropic hardening. In Fig. 2, definitions of the mechanical properties for the reinforcement are presented. The material properties used for the reinforcement in the Toronto panels and the Houston panels are presented in Table 2. From the test of the Toronto panel

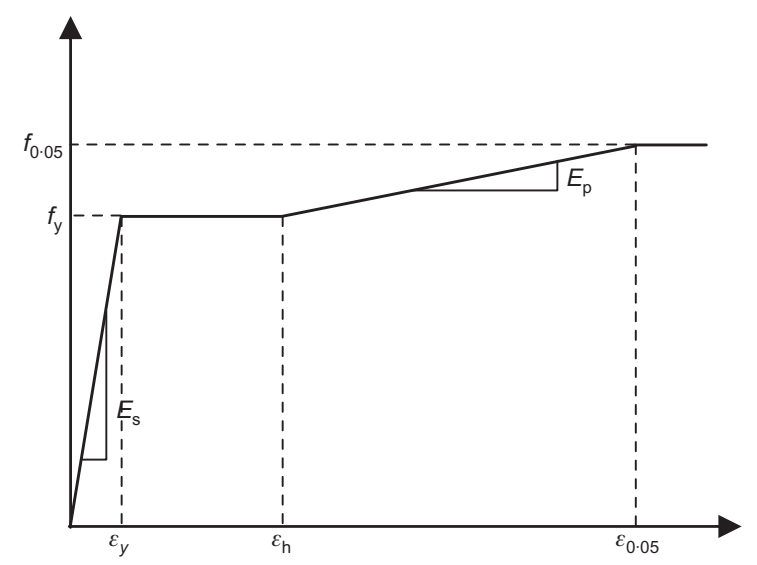

(a)

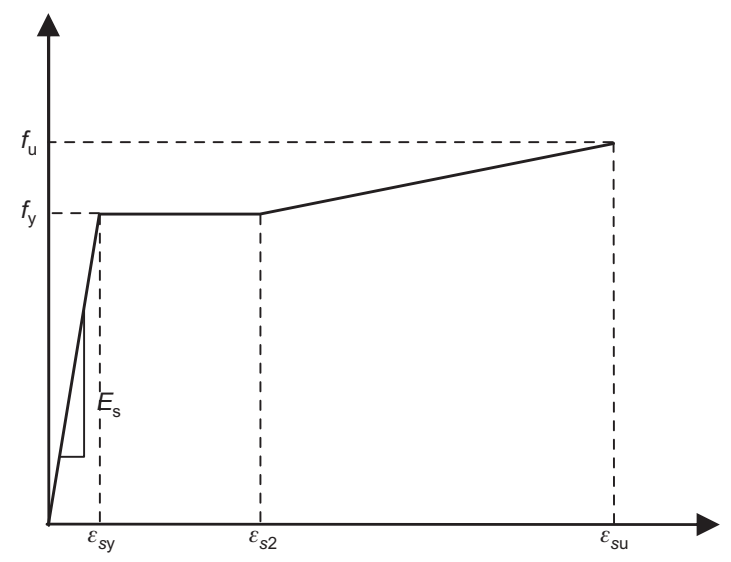

(b)

Fig. 2. Typical stress-strain relationships for reinforcement. Definitions of mechanical properties: (a) panels; (b) beams only the reinforcement strength was reported and the modulus of elasticity was chosen as $200 \mathrm{GPa}$ for all reinforcement. In Table 3, the material properties of the reinforcement used for the beam analyses are presented. No hardening parameters were presented for the reinforcement used in the box-beam test. Instead, the values presented in Table 3 are mean values taken from several other test reports using the same kind of reinforcement, from the same laboratory and the same time period.

\section{Finite-element analyses of shear panel tests}

Tests

Three shear panel tests were simulated out of 30 of the Toronto panels by Vecchio and Collins, ${ }^{1}$ labelled PV10, PV19 and PV20. From the Houston panels by Pang and $\mathrm{Hsu}^{16}$ and Pang, ${ }^{32}$ four tests were simulated, labelled A3, B1, B2 and B4. The specimens tested in Toronto were $0.89 \mathrm{~m}$ square and $0.07 \mathrm{~m}$ thick; they were reinforced with two layers of smooth welded wire mesh. The specimens analysed here were loaded in pure shear; see Fig. 3(a). The specimens tested in Houston were $1.4 \mathrm{~m}$ square and $0.178 \mathrm{~m}$ thick. They were reinforced in two layers of deformed bars spaced at $0.189 \mathrm{~m}$ in two directions. The loading, equal in compression and in tension, was applied in the principal directions and the reinforcement was orientated with $45^{\circ}$ inclination, resulting in the same stress situation as in the Toronto panels; see Fig. 3(b). In the Toronto panel tests as well as in the Houston panel tests, the loads were applied by hydraulic jacks connected to shear keys that were welded to the reinforcement. It is worth noting that the reinforcement ratios in the two test series are quite similar, see Table 2. The Toronto panels are thin with closely spaced reinforcement of small bar diameters and of a low-strength con-

Table 2. Material properties for reinforcement used in the analyses of the Toronto panel tests (PV10, PV19 and PV20) and the Houston panel tests (A3, B1, B2 and B4)

\begin{tabular}{|c|c|c|c|c|c|c|c|c|}
\hline Test & & $\rho$ & $f_{\mathrm{y}}: \mathrm{MPa}$ & $E_{\mathrm{s}:} \mathrm{GPa}$ & $f_{0.05}: \mathrm{MPa}$ & $\varepsilon_{y}$ & $\varepsilon_{\mathrm{h}}$ & $E_{\mathrm{p}:} \mathrm{GPa}$ \\
\hline \multirow[t]{2}{*}{ PV10 } & Long $(x-)$ & $0 \cdot 01790$ & 276 & 200 & - & - & - & - \\
\hline & Trans $(y-)$ & 0.01000 & 276 & 200 & - & - & - & - \\
\hline \multirow[t]{2}{*}{ PV19 } & Long $(x-)$ & $0 \cdot 01790$ & 458 & 200 & - & - & - & - \\
\hline & Trans $(y-)$ & 0.00710 & 299 & 200 & - & - & - & - \\
\hline \multirow[t]{2}{*}{ PV20 } & Long $(x-)$ & $0 \cdot 01790$ & 460 & 200 & - & - & - & - \\
\hline & Trans $(y-)$ & $0 \cdot 00890$ & 297 & 200 & - & - & - & - \\
\hline \multirow[t]{2}{*}{ A3 } & Long $(x-)$ & $0 \cdot 01789$ & 446 & 200 & 625 & $0 \cdot 0022$ & $0 \cdot 0111$ & $4 \cdot 60$ \\
\hline & Trans $(y-)$ & 0.01789 & 446 & 200 & 625 & 0.0022 & $0 \cdot 0111$ & $4 \cdot 60$ \\
\hline \multirow[t]{2}{*}{ B1 } & Long $(x-)$ & 0.01193 & 462 & 192 & 609 & $0 \cdot 0024$ & $0 \cdot 0144$ & $3 \cdot 73$ \\
\hline & Trans $(y-)$ & $0 \cdot 00596$ & 444 & 181 & 579 & $0 \cdot 0044$ & - & $2 \cdot 69$ \\
\hline \multirow[t]{2}{*}{ B2 } & Long $(x-)$ & $0 \cdot 01789$ & 446 & 200 & 625 & $0 \cdot 0022$ & $0 \cdot 0111$ & $4 \cdot 60$ \\
\hline & Trans $(y-)$ & $0 \cdot 01193$ & 462 & 192 & 609 & $0 \cdot 0024$ & $0 \cdot 0144$ & $3 \cdot 73$ \\
\hline \multirow[t]{2}{*}{ B4 } & Long $(x-)$ & 0.02982 & 469 & 200 & 629 & $0 \cdot 0023$ & 0.0073 & $3 \cdot 76$ \\
\hline & Trans $(y-)$ & 0.00596 & 444 & 181 & 579 & $0 \cdot 0044$ & - & $2 \cdot 69$ \\
\hline
\end{tabular}


Table 3. Material properties for reinforcement used in the analyses of the beam tests

\begin{tabular}{l|l|c|c|c|c|c|c}
\hline Test & Dimension and quality & $f_{\mathrm{y}}: \mathrm{MPa}$ & $f_{\mathrm{u}}: \mathrm{MPa}$ & $\varepsilon_{\mathrm{sy}:} \%$ & $\varepsilon_{\mathrm{s} 2:} \%$ & $\varepsilon_{\text {su: }} \%$ & $E_{\mathrm{s}:} \mathrm{GPa}$ \\
\hline Beam 5 & $\frac{1}{2}$ in. St 150/170 & 1840 & - & - & - & - & $207 \cdot 0$ \\
& $\phi$ 8 Ks40s & 456 & $600^{*}$ & $2 \cdot 09$ & - & $150^{*}$ & $218 \cdot 0$ \\
\multirow{2}{*}{ NSC 3 } & $\phi 16 \mathrm{Ks60}$ & 710 & $900^{*}$ & $3 \cdot 05$ & - & $110^{*}$ & $233 \cdot 0$ \\
& $\phi$ 8 K500 ST & 468 & 670 & $3 \cdot 10$ & $29 \cdot 3$ & 99 & $199 \cdot 8$ \\
& $\phi$ 20 K500 ST & 600 & $2 \cdot 40$ & $21 \cdot 5$ & 132 & $195 \cdot 6$ \\
\hline
\end{tabular}

*Values taken as a mean value of test values from several other reports using same kind of reinforcement.

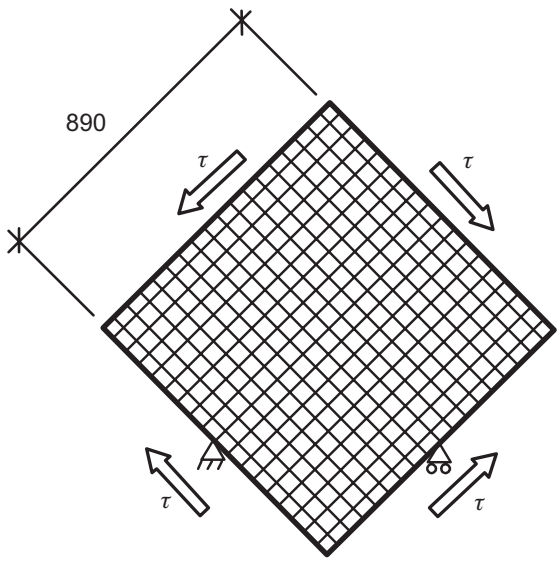

(a)

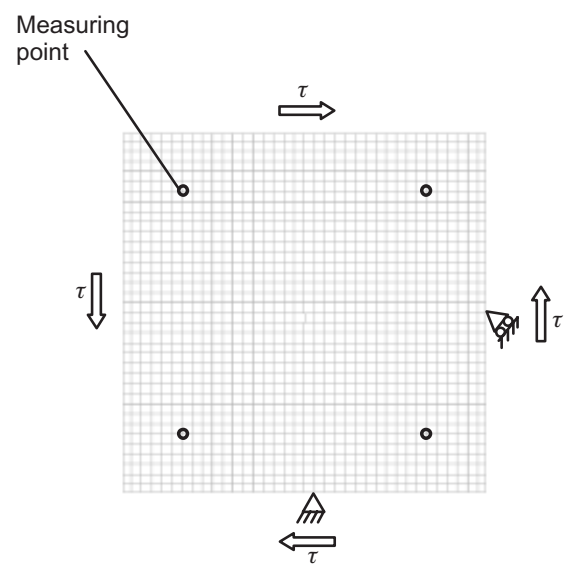

(c)

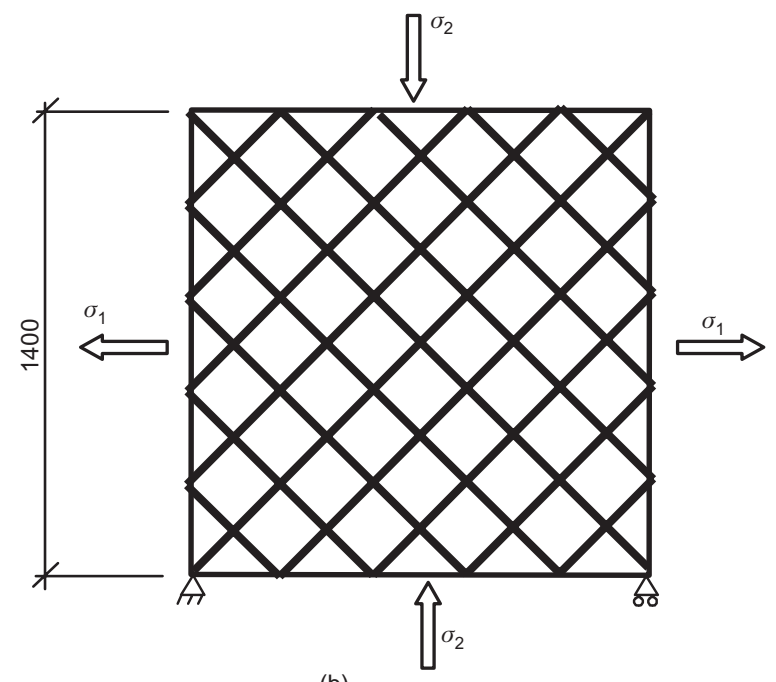

(b)

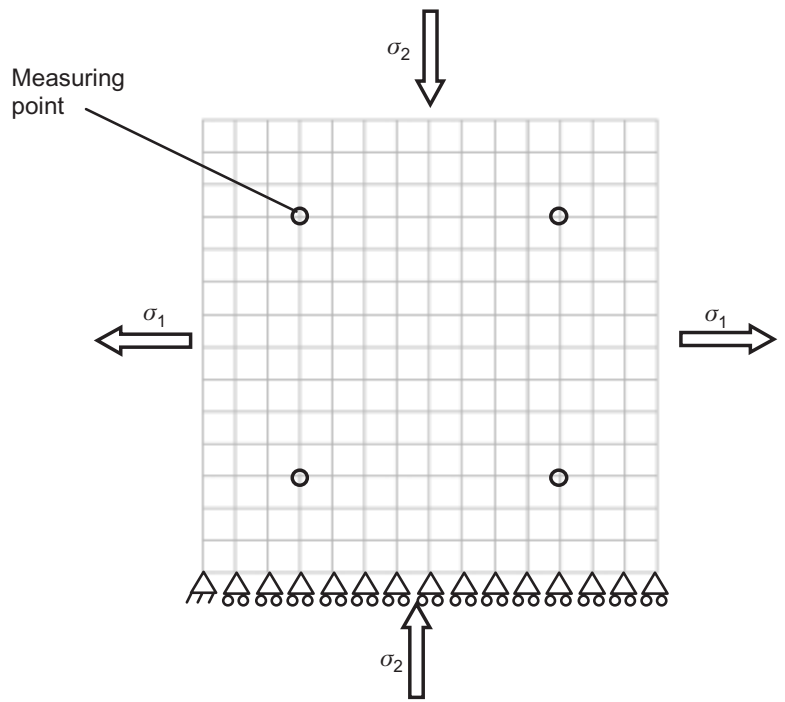

(d)

Fig. 3. Principal testing arrangement of (a) the Toronto shear panels PV10, PV19 and PV20; (b) the Houston shear panels A3, B1, B2 and B4. The principle of the FE models used to analyse (c) the Toronto panels; (d) the Houston panels

crete and could thus be seen as made in a model scale compared with the Houston panels. This is reflected in the FE analyses since measured concrete compressive strength and estimated crack distances determined the concrete properties used, see above section on modelling technique.

\section{FE models}

Diagrammatic representations of the FE models used to analyse the Toronto panels and the Houston panels are given in Fig. 3. The loads were equally distributed on each side and applied at each node as shear, tension or compression in accordance with each

Magazine of Concrete Research, 2007, 59, No. 9 
test procedure respectively. The panels were supported as shown in Fig. 3. In the analyses, the self-weight was applied in one step and then the load was applied in steps of $1 \mathrm{kN}$ for the Toronto panels and $5 \mathrm{kN}$ for the Houston panels. This corresponds to a shear stress of approximately $16 \mathrm{~Pa}$ and $20 \mathrm{~Pa}$ respectively.

\section{Results}

From the analyses, the shear strains, $\gamma$, were calculated from $\varepsilon_{x}$ and $\varepsilon_{y}$ or from $\varepsilon_{1}$ and $\varepsilon_{2}$ in accordance with how they were calculated in the Toronto panel tests and the Houston panel tests respectively; see Fig. 4. In the tests and in the analyses, the elongation between the measuring points (see Fig. 3) was used to calculate the average strains. In Figs 5-9, results from the analysis of tests PV10, PV19 and PV20 are compared with results from the tests as presented in Vecchio et al. ${ }^{33}$ and Vecchio and Lai. ${ }^{34}$ In Figs 10 and 11, the results from the analysis of tests A3, B1, B2 and B4 are compared with results from the tests as presented in Pang. ${ }^{32}$

Comparing results such as the applied shear stress plotted against shear strain shows that four-node curved shell elements combined with embedded reinforcement can describe the shear response. Furthermore, with only fracture energy of plain concrete taken into account, the capacity was underestimated and the average strains - that is, the crack widths - were overestimated. On the other hand, if the concrete contribution was modelled with a tension-softening curve modified according to the expression from MCFT, the capacity was overestimated and the average strains were underestimated for most panels, except for the Toronto panels. It should be mentioned that results from the Toronto panel tests have been included in the test results used

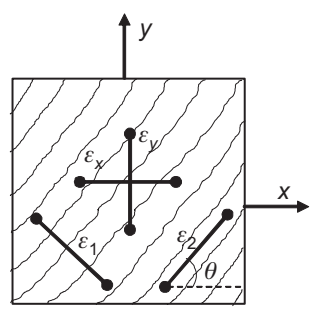

(a)
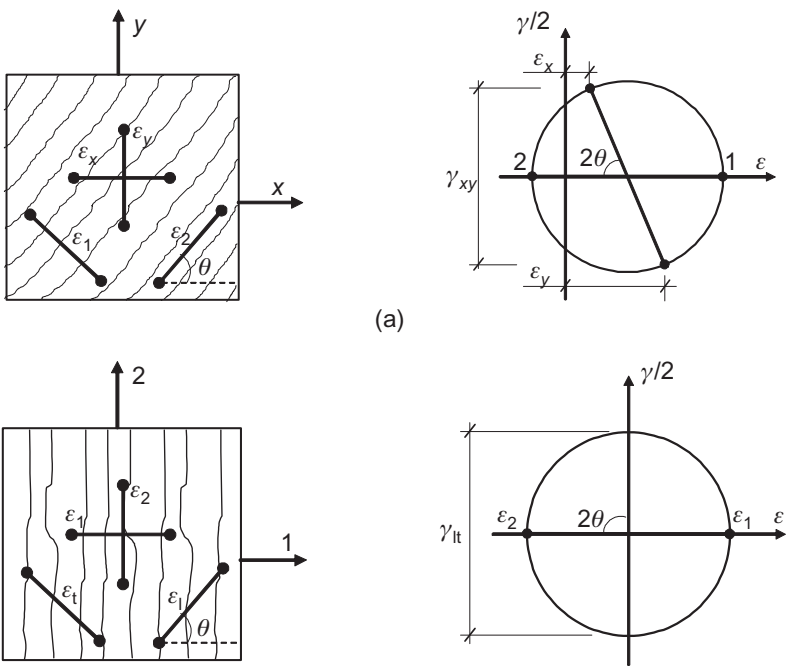

(b)

Fig. 4. The shear strains from the analyses, $\gamma_{x y}$ and $\gamma_{l t}$, were calculated from $\varepsilon_{x}$ and $\varepsilon_{y}$ or from $\varepsilon_{1}$ and $\varepsilon_{2}$, respectively, with Mohr's strain circle in accordance with how they were calculated in (a) the Toronto panel tests and (b) the Houston panel tests

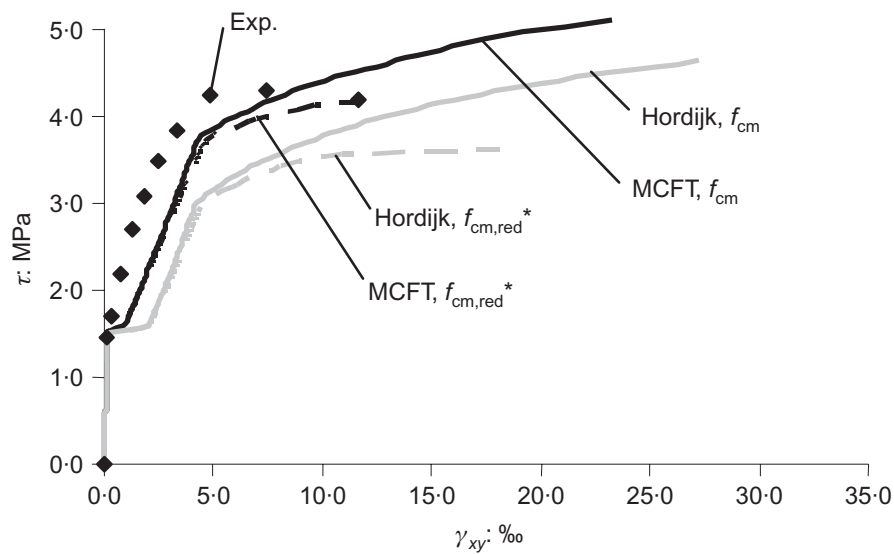

(a)

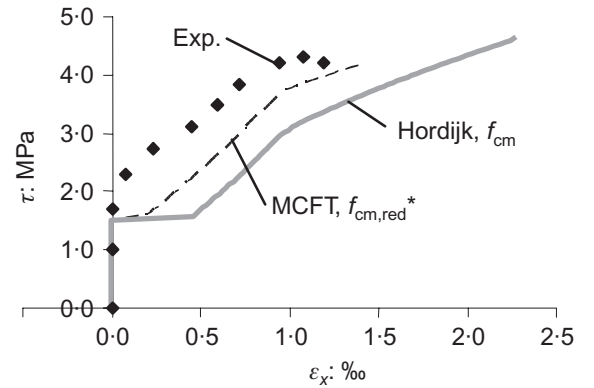

(b)

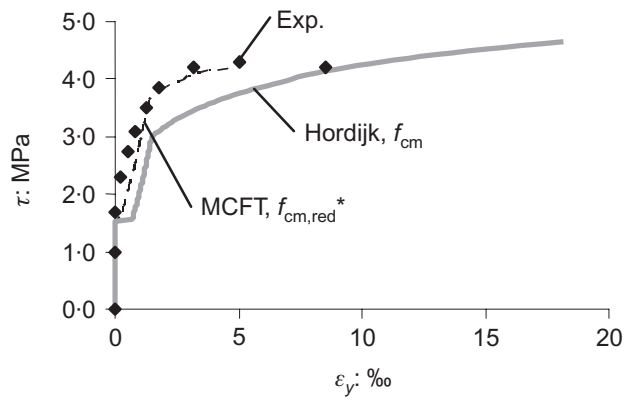

(c)

Fig. 5. Comparison of results from test and analysis of PV20, applied shear stress plotted against (a) shear strain, (b) longitudinal strain, $\varepsilon_{x}$, (c) transversal strain, $\varepsilon_{y} .{ }^{*}$ The compressive strength is reduced owing to transverse tensile strains 


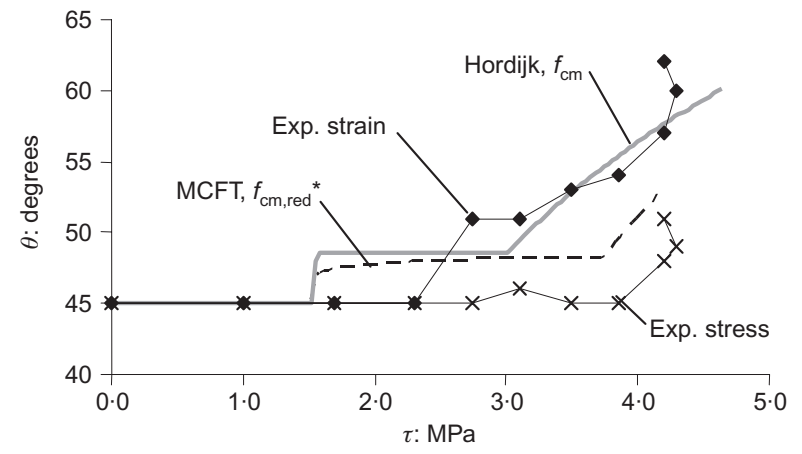

Fig. 6. Comparison of results from test and analyses for PV20, applied shear stress against principal strain direction and principal stress direction. *The compressive strength is reduced owing to transverse tensile strains

to calibrate the expression in the MCFT. This means that the concrete contribution to the shear capacity can be accounted for by modifying the constitutive relationship used for concrete in tension. However, caution is recommended in order not to overestimate the capacity. The modification needs to take the reinforcement (type, diameter and spacing) and possibly also the concrete composition (strength, grading curve and maximum aggregate size) into account. If no modification of the tension-softening curve is performed, the shear capacity will at least not be overestimated. Moreover, it was found that it is important to include the reduction of compression strength owing to transverse tensile strain. This influenced the behaviour and, if the failure mode was crushing of the concrete between the shear cracks, also the capacity; see Fig. 8.

When the cracking was initiated, the concrete shear strain started to increase just like the steel stress in the reinforcement. The steel stresses in the transverse reinforcement, which is in the direction with the lowest reinforcement amount, increased faster than the steel stresses in the longitudinal reinforcement, see Figs 7-9 and 11 . In the tests and the analyses before cracking, the applied shear stress was equal to the principal tensile stress. Thus, the cracking was expected to start when the principal tensile stress reached the concrete tensile strength. This was also the case for the Toronto panel tests. However, for the Houston panel tests, cracking started for a much lower concrete principal tensile stress than could be expected from the mean compressive cylinder strength according to fib. ${ }^{21}$ The analyses by Soltani et ll. $^{20}$ show much better agreement, since here the concrete tensile strength was chosen as the cracking strength obtained in the tests. In Fig. 10(c), results from analyses using the cracking strength instead of the calculated tensile strength are shown. The tensile strength is an important material property for prediction of when the cracking starts, but it is less important for the capacity. The low cracking

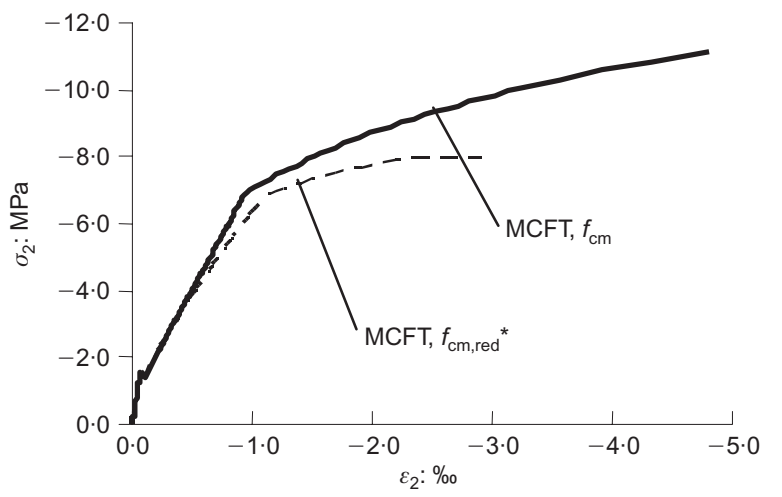

(a)

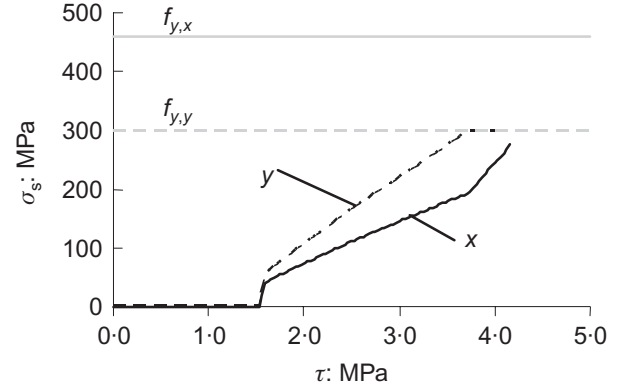

(b)

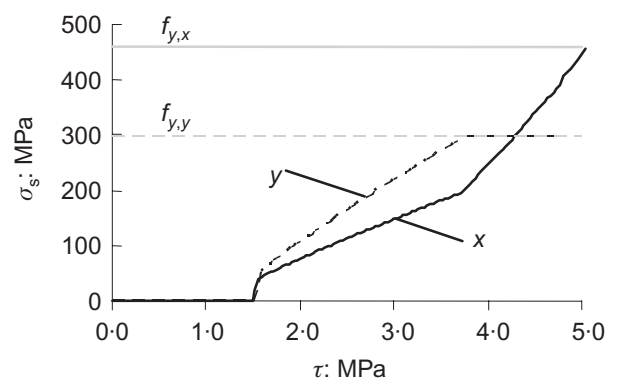

(c)

Fig. 7. Results from FE analyses of PV20: (a) principal compression stress plotted against principal compression strain in one element; (b) and (c) applied shear stress plotted against steel stress in longitudinal ( $x$-) and vertical (y-) reinforcement, MCFT (b) with and (c) without reduction of the concrete compressive strength owing to transverse strain respectively. *The compressive strength is reduced owing to transverse tensile strains 


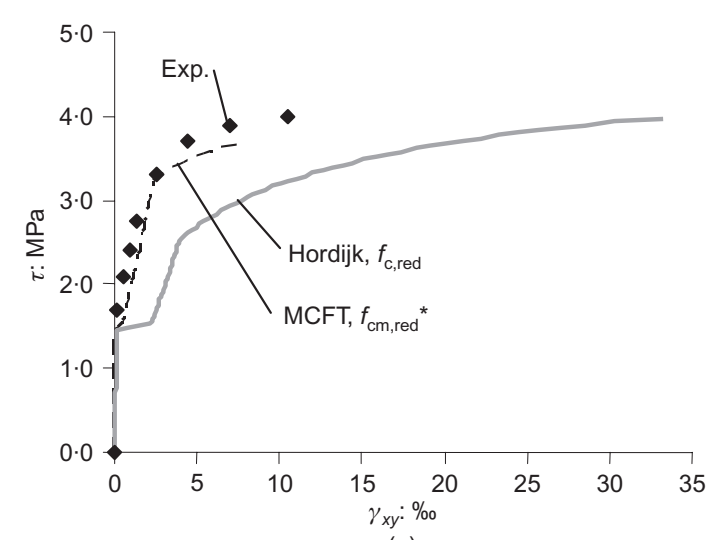

(a)

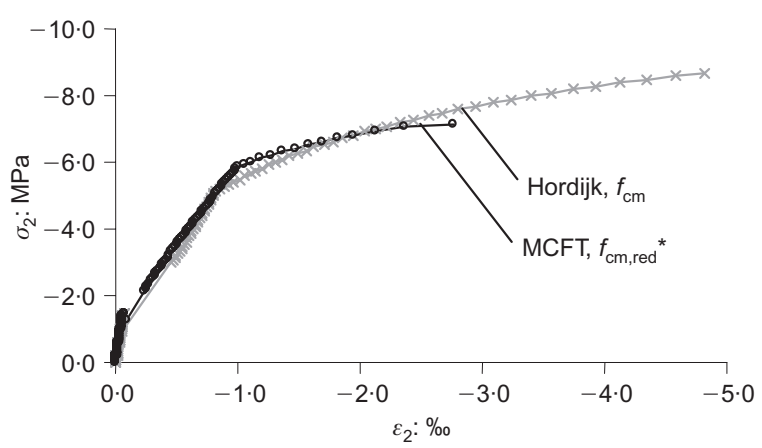

(b)

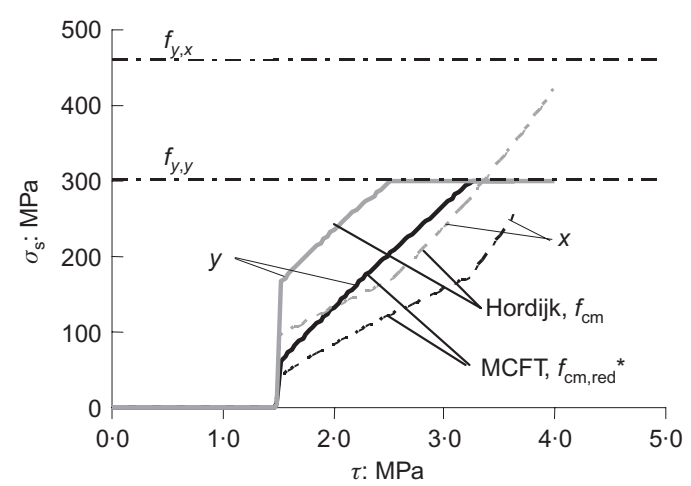

(c)

Fig. 8. Results from FE analyses of PV19: (a) applied shear stress plotted against shear strain; (b) principal compressive stress plotted against principal compression strain;

(c) applied shear stress plotted against steel stress in longitudinal ( $x$-) and vertical (y-) reinforcement. *The compressive strength is reduced owing to transverse tensile strains

strengths reported from the tests may be attributed to initial internal stresses caused by shrinkage, or to local effects introduced by the shear keys.

The stiffness of the panel decreased and the direction of the principal stress and the principal strain changed when the panel started to crack. This became even more pronounced when the weakest reinforcement started to yield. From the Toronto panel test it was found that the principal strain direction deviated from the principal stress direction; see Fig. 6. The direction of the principal compressive stress in concrete was

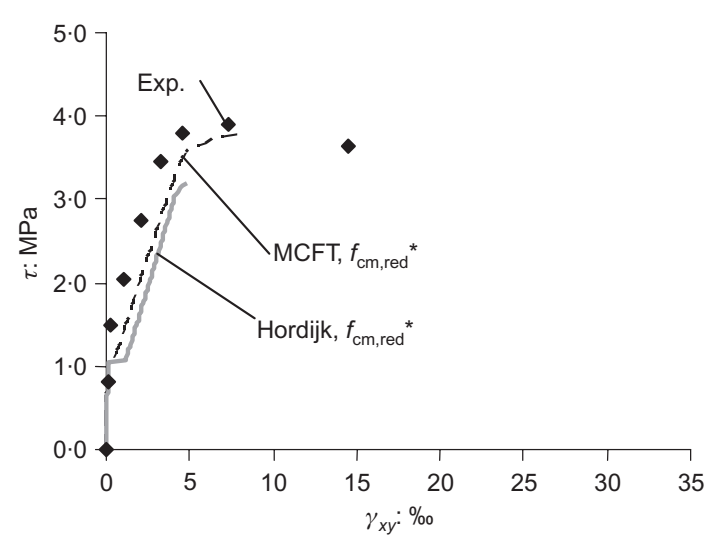

(a)

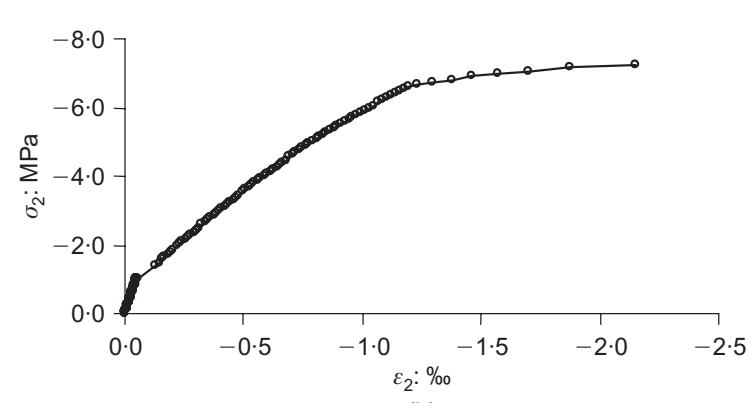

(b)

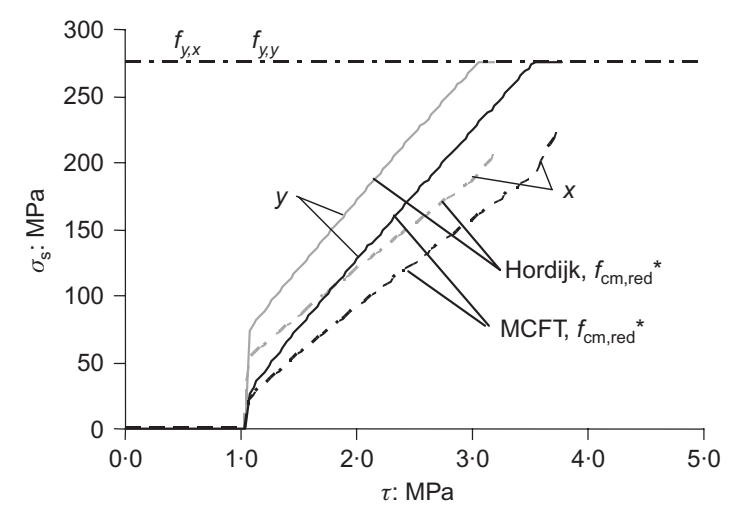

(c)

Fig. 9. Results from FE analyses of PV10: (a) applied shear stress plotted against shear strain; (b) principal compression stress plotted against principal compression strain;

(c) applied shear stress plotted against steel stress in longitudinal ( $x$-) and vertical (y-) reinforcement. ${ }^{*}$ The compressive strength is reduced owing to transverse tensile strains

calculated from the applied loads and the measured steel strains. In a rotating crack model that was used here, the principal strain direction and the principal stress direction are the same by definition.

\section{Finite-element analyses of a box-beam}

\section{FE model}

To investigate the general applicability of the aboveused analysis method for members with non-orthogonal 


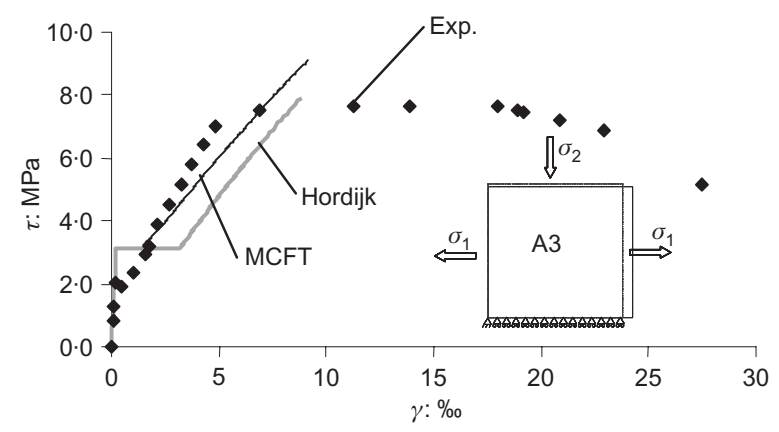

(a)

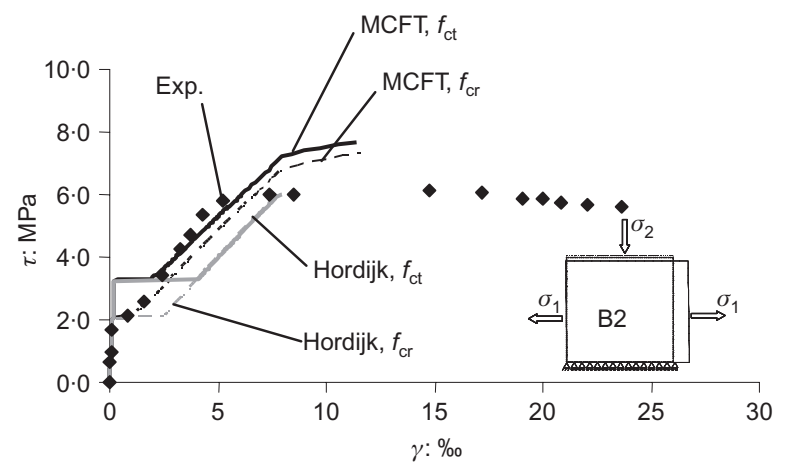

(c)

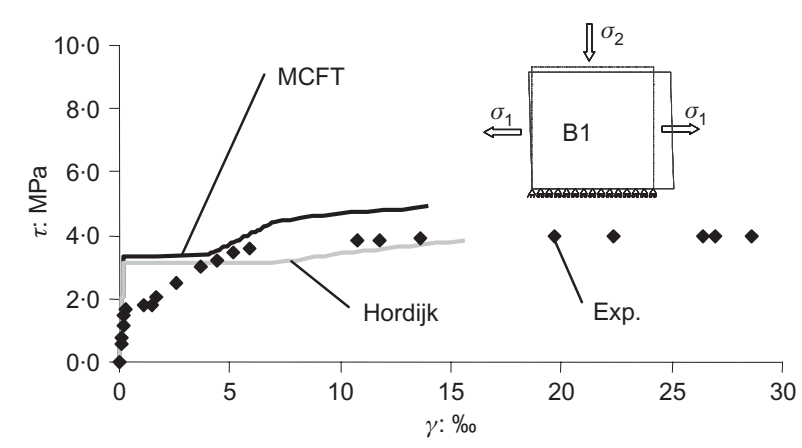

(b)

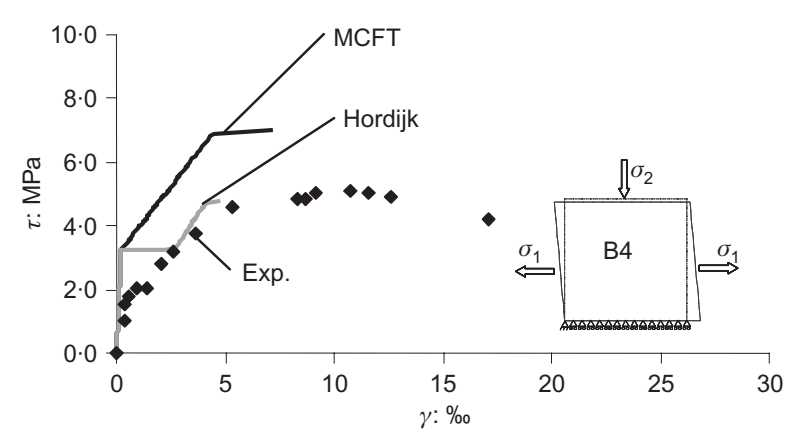

(d)

Fig. 10. Comparison of results from test and analysis of the Houston panels, applied shear stress plotted against shear strain: (a) A3; (b) B1; (c) B2; (d) B4. In all the analyses presented in this figure, the concrete compressive strength was reduced owing to transverse tensile strain

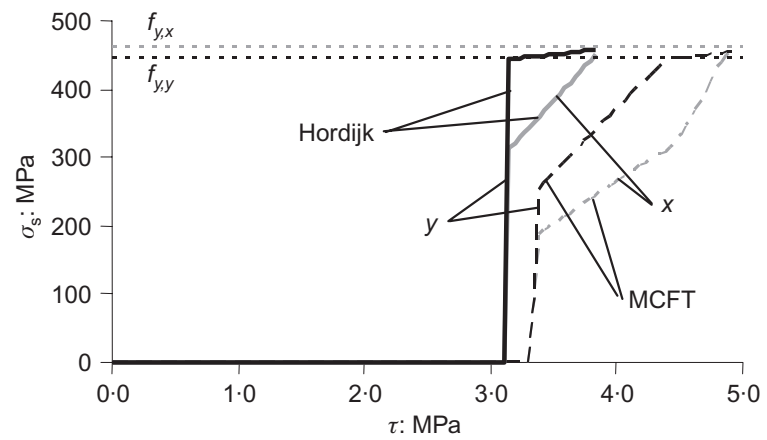

(a)

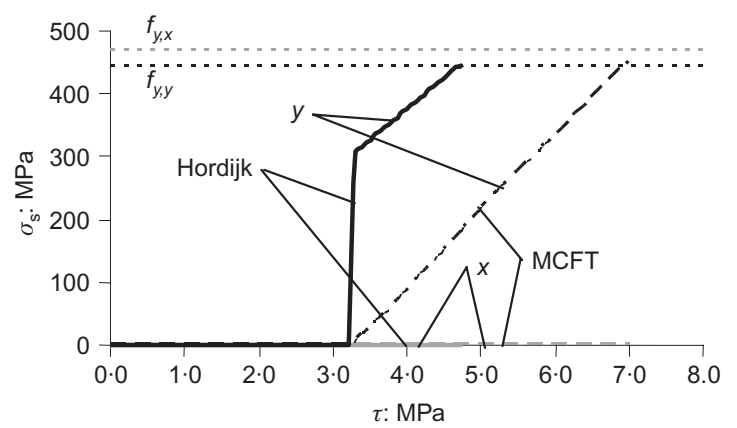

(b)

Fig. 11 Results from FE analyses: applied shear stress plotted against steel stress in longitudinal ( $x$-) and vertical (y-) reinforcement for the Houston panels; (a) B1; (b) B4 reinforcement and subjected to mixed loading effects, a reinforced and prestressed box-beam, beam 5, tested by Karlsson and Elfgren, ${ }^{30}$ was analysed. The box-beam was subjected to bending, shear and torsion and the final failure was attributed to large opening of a shear and torsion crack in the loaded web. Fig. 12 shows the principal arrangement, the dimensions, the support conditions and the FE model of the simulated box-beam.

Owing to symmetry only half of the beam was modelled, as shown in Fig. 12, using curved shell elements and material properties according to Tables 1 and 3 . The box-beam was reinforced as shown in Fig. 12. The prestressing strands and the $8 \mathrm{~mm}$ longitudinal reinforcement bars were modelled as embedded bars, while the rest of the reinforcement was modelled as embedded grids; see $\mathrm{TNO}^{27}$

In the test, the box-beam was supported on roller bearings with a load-distributing support plate. In the analyses, the nodes in the centre of the supports were fixed in the vertical direction. The nodes on each side of this node were forced to have the same vertical displacement but in opposite directions, thus enabling a rotation and simulating a free support with a distribution length equal to the support plate in the test.

Stiffeners at the support, and at the mid-span where the load was applied, were taken into account as fol-

Magazine of Concrete Research, 2007, 59, No. 9 

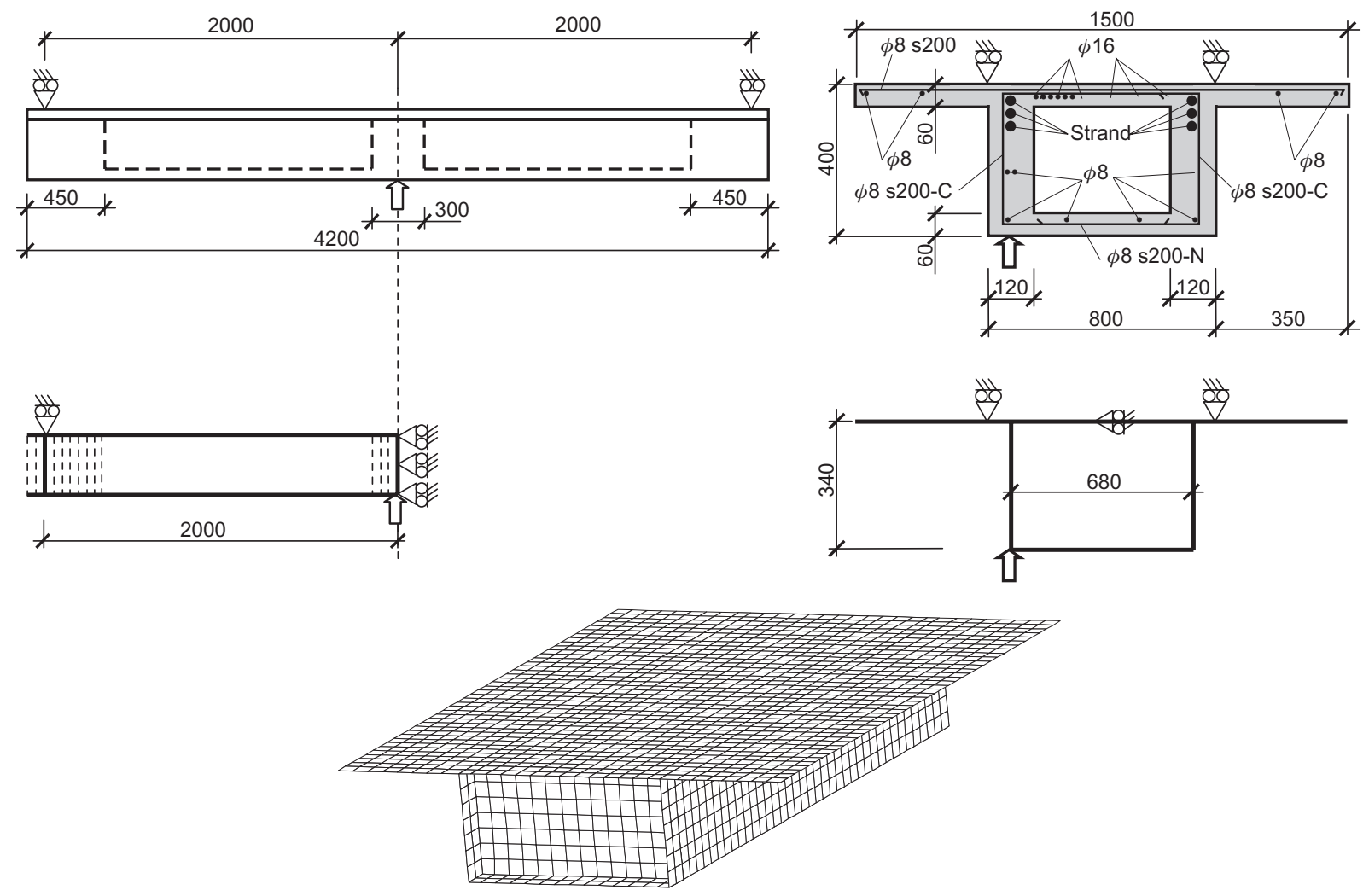

Fig. 12. Principal testing arrangement and FE model of the prestressed box-beam, beam 5

lows. All shell elements for the box wall and flanges in the area of the stiffeners were given a thickness twice the thickness of the elements outside these parts. The density of the concrete was also modified to maintain the correct self-weight of the box-beam. Furthermore, all nodes in each cross-section of the stiffened areas were tied to keep the cross-section plane.

In the box-beam test, the load was applied in steps of $40 \mathrm{kN}$ up to $320 \mathrm{kN}$. Thereafter, the load was increased by controlling the mid-deflection in steps of $1-2.5 \mathrm{~mm}$. In the analyses, the load was applied as a prescribed deformation of the loading node - that is, the bottom corner node in the symmetry section. The box-beam analysis had to be performed in two phases. In the first phase, the loading node was not supported; here the prestressing force $(110 \mathrm{kN})$ was released and the selfweight was applied. In the second phase, the loading node was supported vertically at the location obtained in the first phase. Thereafter, the loading was applied by increasing the vertical displacement of the loading node.

In the analyses of the box-beam, concrete compressive failure was localised into one element. The size of this element does not correspond to the size of the specimens used to calibrate the compression relationship by Thorenfeldt as described in TNO. ${ }^{27}$ Consequently, if the relationship by Thorenfeldt was used, the model could not predict the response. This disadvantage was overcome by modelling the concrete in compression with an elastic-ideal plastic relationship instead.
Results

The applied load plotted against vertical displacements from the analyses and the test are compared in Fig. 13. The results show, as expected, that if only the fracture energy of plain concrete was taken into account, the capacity was underestimated and the vertical deflections were overestimated. However, when the concrete contribution was modelled with the expression from MCFT, the capacity was still underestimated but the vertical deflections agreed well.

In the test, the first crack, going in the transverse direction across the top flange, occurred at a load of

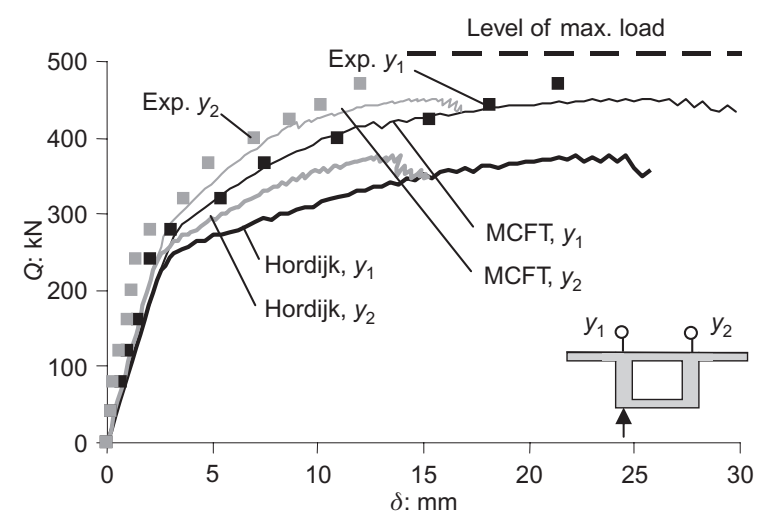

Fig. 13. Comparison of results from test and analyses of a prestressed concrete box-beam subjected to bending, shear and torsion; applied load plotted against mid-deflections 
$240 \mathrm{kN}$ owing to bending. This crack propagated down in the most loaded web at a load of $280 \mathrm{kN}$. At a load of $320 \mathrm{kN}$ the first shear and torsion crack appeared near the support. The final failure, at a load of $510 \mathrm{kN}$, was attributable to large opening of a shear and torsion crack in the loaded web. The angle of the cracks in the most loaded web varied between 45 and $60^{\circ}$, while they remained vertical in the other web. The crack propagation and the crack pattern from both analyses agreed well with those observed in the test.

In Fig. 14, the load plotted against steel strains for one strand and one stirrup, from the test and the analyses, are compared. The steel strain increased first when the box-beam started to crack. In the analysis with the tension softening modelled according to MCFT, the steel strain increase was slower, which corresponds better with the steel strains measured in the test.

\section{FE analysis of a bending beam}

\section{FE model}

To investigate the general applicability of the above analysis method for members that do not fail due to shear

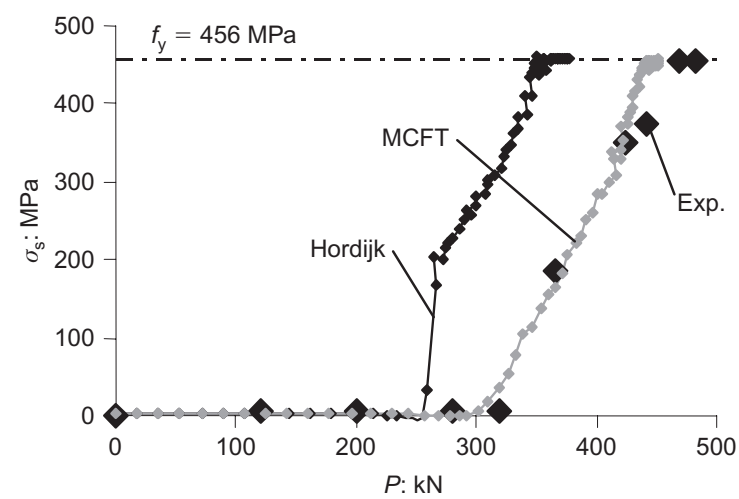

(a)

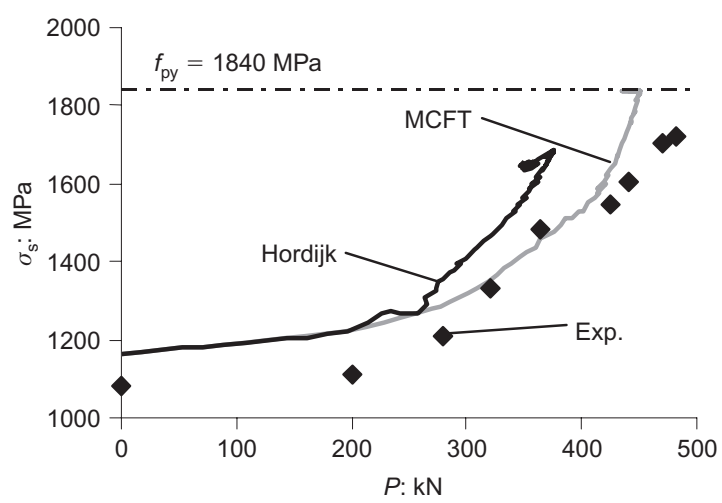

(b)

Fig. 14. Comparison of results from test and analyses of a prestressed concrete box-beam subjected to bending, shear and torsion; applied load plotted against steel stresses in loaded web; (a) stirrup $400 \mathrm{~mm}$ from load, (b) top prestressing strand cracks, a four-point bending beam, NSC3, tested by Magnusson, ${ }^{31}$ was simulated. The bending beam was subjected to bending and shear, and failed in bending owing to yielding of the longitudinal reinforcement and crushing of the concrete in the compressive zone in the mid-span part of the beam. Fig. 15 shows the dimensions and support conditions of the simulated bending beam.

Owing to symmetry, only half of the beam was modelled, as shown in Fig. 16, using curved shell elements and material properties according to Tables 1 and 3. The beam was reinforced as shown in Fig. 15. The longitudinal reinforcement and the stirrups between the support and the load were modelled as embedded bars, while the stirrups in the middle part of the beam were modelled as an embedded grid, see TNO. ${ }^{27}$ The supports were modelled in the same way as for the box-beam.

The loading of the bending beam was controlled by displacement both in the test and in the analysis. In the analysis, the loading was applied by increasing the vertical displacement of the loading node in steps of $0.1 \mathrm{~mm}$. In the test, the load was distributed by a loading plate. In the analyses, this was simulated in the same way as for the box-beam.

Also in the bending beam analyses, compressive failure was localised in one element. Therefore, the concrete in compression was modelled with an elasticideal plastic relationship instead of the curve by Thorenfeldt. The element in which high compressive strains were localised was also subjected to large lateral strains owing to a flexural shear crack. This flexural shear crack was also observed in the test, but there it did not go into the compressive zone. Consequently, reducing the compressive strength owing to lateral strains resulted in an unreasonable response. Therefore, for these analyses, the compressive strength was not reduced.

\section{Results}

The relations between the applied load and the vertical displacements from the analyses and the test are compared in Fig. 17. With only the fracture energy of plain concrete taken into account, the capacity is very well estimated and the behaviour is just a little bit too stiff. However, when the tension softening was modelled according to MCFT, the behaviour was too stiff and the capacity was overestimated. The reason was that, in this case, the cracked concrete transferred tensile stresses over the bending cracks even after the longitudinal reinforcement had started to yield.

The conclusion is that if a tension-softening curve including the concrete contribution to shear capacity is used, it needs to be modified, so that no tensile stresses are transferred when the reinforcement yields. Otherwise the capacity will be overestimated for the parts of a member which are subjected to tension or bending. Furthermore, even if the curve is modified with respect to reinforcement yielding, it will lead to a too stiff response after cracking and before yielding.

Magazine of Concrete Research, 2007, 59, No. 9 


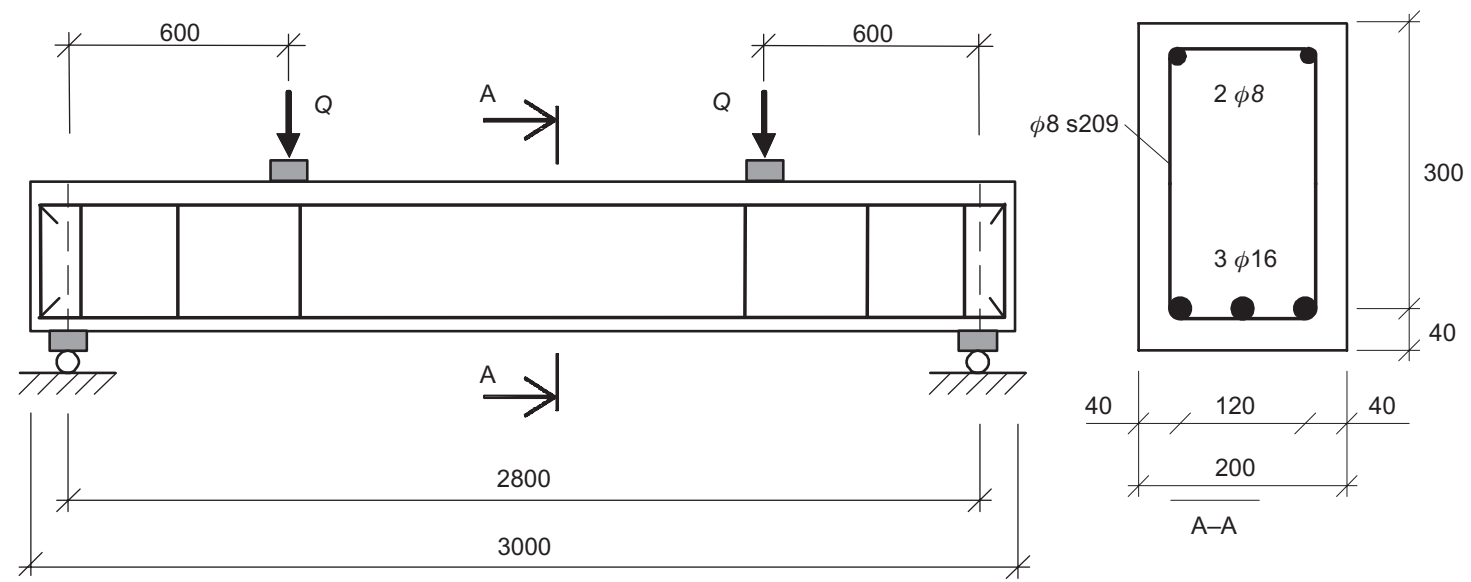

Fig. 15. Principal testing arrangement of the four-point bending beam, NSC3

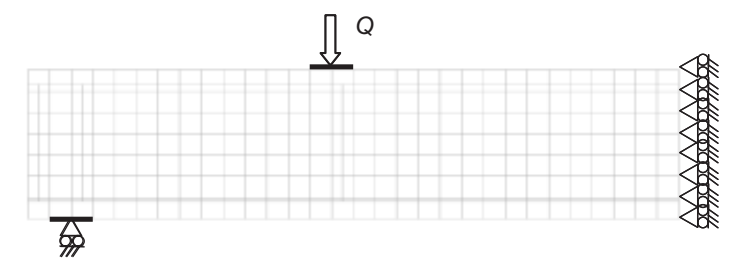

Fig. 16. FE model of the four-point bending beam, NSC3

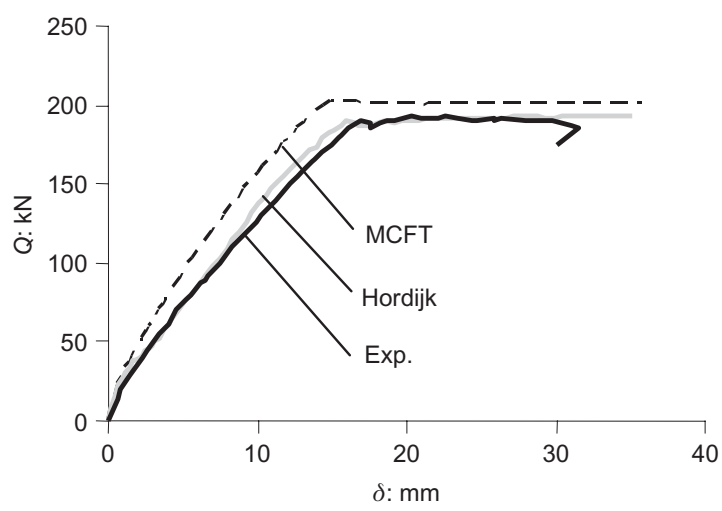

Fig. 17. Comparison of results from test and analyses of a reinforced concrete beam subjected to bending; applied load plotted against mid-deflection

\section{Conclusions}

It is well known that the shear capacity determined by sliding along inclined cracks is larger than can be explained by the reinforcement contribution determined from a truss model. This increase in shear stiffness and shear capacity is attributable to tension stiffening, dowel action and friction owing to aggregate interlock, and is also known as the concrete contribution. If the shear response is simulated with non-linear FEM, with a model not specially designed for shear analysis, the concrete contribution has in the past been accounted for by modifying the constitutive relationships used, for example the tension-softening curve describing the concrete behaviour in tension.
In the present study, the commercial FE program DIANA was used to simulate the non-linear response in experiments of several shear panels, a prestressed boxbeam subjected to shear, torsion and bending, and an $\mathrm{RC}$ beam subjected to bending and shear. It was shown that four-node curved shell elements with embedded reinforcement could describe the non-linear shear response for panels loaded in shear and also for prestressed members loaded in bending, shear and torsion. Results from the analyses showed that, if only the fracture energy of plain concrete was taken into account, the capacity was well predicted and the average strains - that is, the crack widths - were well reflected for the bending beam and one shear panel. For all other specimens studied, the shear capacity was underestimated and the average strains were overestimated. On the other hand, if the concrete contribution to the shear capacity was considered with the expression from MCFT, the capacity was in many cases overestimated and the average strains underestimated, except for the Toronto panels. It should be mentioned that results from the Toronto panel tests have been included in the test results used to calibrate the expression in the MCFT. This means that the concrete contribution to the shear capacity can be accounted for by modifying the constitutive relationship used for concrete in tension. However, caution is recommended in order not to overestimate the capacity. If no modification of the tensionsoftening curve is undertaken, the shear capacity will at least not be overestimated.

The analysis results from the shear panels showed that it was important to include the reduction of the compression strength due to transverse tensile strain for the behaviour, and also for the capacity if the failure mode was crushing of the concrete between the shear cracks. Furthermore, it was shown that the stiffness of the panel decreased and the direction of the principal stress and the principal strain changed when the panel started to crack. This became even more pronounced when the weakest reinforcement started to yield.

The analyses of the box-beam showed that if only 
the fracture energy of plain concrete was taken into account, the capacity was underestimated and the vertical deflections were overestimated. However, when the concrete contribution was considered with the expression from MCFT, the capacity was still underestimated but the vertical deflections agreed well.

By simulating a test of a four-point bending beam that failed in bending, it was found that when the concrete contribution was considered according to MCFT, the behaviour was too stiff and the capacity was overestimated. Hence, the cracked concrete transferred tensile stresses even when the longitudinal reinforcement yielded. In the analyses of the boxbeam and the bending beam, concrete compressive failure was localised into one element, whose size did not correspond to the size of the specimens used to calibrate the compression relationship used-that is, the non-linear tension-softening curve by Thorenfeldt. Hence, if the relationship by Thorenfeldt was used, the model could not predict the response. This disadvantage was overcome by modelling the concrete in compression with an elastic-ideal plastic relationship instead. In the bending beam analyses, the element in which high compressive strains were localised was also subjected to large lateral strains owing to a flexural shear crack. This flexural shear crack was also observed in the test, but there it did not go into the compressive zone. Consequently, reducing the compressive strength owing to lateral strains resulted in an unreasonable response. Therefore, for these analyses, the compressive strength was not reduced.

In summary, the present study implies that an analysis of a concrete member subjected to shear, torsion and bending will be on the safe side when evaluating the load-carrying capacity or crack widths, if only the fracture energy is used to define the unloading branch of the concrete in tension.

\section{Acknowledgements}

The research was financed by the Swedish Road Administration (Vägverket), the Swedish Rail Administration (Banverket) and Chalmers University of Technology.

\section{References}

1. Vecchio F. J. and Collins M. P. The modified compressionfield theory for reinforced concrete elements subjected to shear. Journal of the American Concrete Institute, 1986, 83, No. 2, 219-231.

2. Comité Européen de Normalisation. CEN/TC250/SC2. Eurocode 2: Design of concrete structures-Part 1: General rules and rules for buildings, prEN 1992-1-1. CEN Brussels, 2004.

3. Gabrielsson H. Ductility of High Performance Concrete Structures. $\mathrm{PhD}$ thesis, Luleå University of Technology, Luleå, Sweden, 1999.

4. PAJARI M. Shear-torsion Interaction Tests on Single Hollow
Core Slabs. Technical Research Centre of Finland, Espoo, 2004, VTT Research Notes 2275.

5. Broo H., Lundgren K. and Engström B. Shear and torsion interaction in prestressed hollow core units. Magazine of Concrete Research, 2005, 57, No. 9, 521-533.

6. Broo H. Shear and Torsion Interaction in Prestressed Hollow Core Slabs. Thesis for the degree of Licentiate of Engineering, Chalmers University of Technology, Göteborg, 2005.

7. Аyоuв A. and Filippou F. C. Nonlinear finite-element analysis of RC shear panels and walls. Journal of Structural Engineering, 1998, 124, No. 3, 298-308.

8. Yамамото T. and Vecchio F. J. Analysis of reinforced concrete shells for transverse shear and torsion. ACI Structural Journal, 2001, 98, No. 2, 191-199.

9. Vecchio F. J. and Shim W. Experimental and analytical reexamination of classical beam tests. Journal of Structural Engineering, 2004, 130, No. 3, 460-469.

10. Kettil P., Ródenas J. J., Aguilera Torres C. and Wiberg N.-E. Strength and deformation of arbitrary beam sections using adaptive FEM. Computers and Structures, 2007, 85, No. 1, 15-29.

11. Plos M. Structural Assessment of the Källösund Bridge Using Finite Element Analysis: Evaluation of the Load Carrying Capacity for ULS. Concrete Structures, Department of Structural and Mechanical Engineering, Chalmers University of Technology, Göteborg, Report 04:1, March 2004.

12. Hegger J., Sherif A. and Görtz S. Investigation of pre- and postcracking shear behavior of prestressed concrete beams using innovative measuring techniques. ACI Structural Journal, 2004, 101, No. 2, 183-192.

13. Vecchio F. J. and Collins M. P. Compression response of cracked reinforced concrete. Journal of Structural Engineering, 1993, 119, No. 12, 3590-3610.

14. Belarbi A. and Hsu T. T. C. Constitutive laws of softened concrete in biaxial tension-compression. ACI Structural Journal, 1995, 92, No. 5, 562-573.

15. ASCE-ACI COMmitTeE 445 ON SHeAR AND Torsion. Recent approaches to shear design of structural concrete. Journal of Structural Engineering, 1998, 124, No. 12, 1375-1417.

16. PANG X.-B. D. and HsU T. T. C. Behavior of reinforced concrete membrane elements in shear. ACI Structural Journal, 1995, 92 No. 6, 665-679.

17. Prisco M. D. and Gambarova P. G. Comprehensive model for study of shear in thin-webbed RC and PC beams. Journal of Structural Engineering, 1995, 121, No. 12, 1822-1831.

18. Walraven J. and Stroband J. The behaviour of cracks in plain and reinforced concrete subjected to shear. Proceedings of the 5th International Symposium on Utilization of High Strength/High Performance Concrete, Sandefjord, Norway, 1999, pp. 701-708.

19. ZARARIS P. D. Concrete shear failure in reinforced-concrete elements. Journal of Structural Engineering, 1996, 122, No. 9, 1006-1015

20. Soltani M., An X. and Maekawa K. Computational model for post cracking analysis of RC membrane elements based on local stress-strain characteristics. Engineering Structures, 2003, 25, No. 8, 993-1007.

21. International Federation for Structural Concrete (FIB). Structural Concrete. Textbook on Behaviour, Design and Performance Updated Knowledge of the CEB/FIP Model Code 1990, Vol. 2. fib, Lausanne, Switzerland, 1999.

22. Vecchio F. J. Disturbed stress field model for reinforced concrete: formulation. Journal of Structural Engineering, 2000, 126, No. 9, 1070-1077.

23. Kaufmann W. and Marti P. Structural concrete: cracked membrane model. Journal of Structural Engineering, 1998, 124, No. 12, 1467-1475.

24. PANG X.-B. D. and Hsu T. T. C. Fixed angle softened truss model for reinforced concrete. ACI Structural Journal, 1996, 93, No. 2, 197-207. 
25. Hsu T. T. C. and ZHU R. R. H. Softened membrane model for reinforced concrete elements in shear. ACI Structural Journal, 2002, 99, No. 4, 460-469.

26. LACKNer R. and MANG H. A. Scale transition in steel-concrete interaction. I: Model. Journal of Engineering Mechanics, 2003, 129, No. 4, 393-402.

27. TNO. DIANA Finite Element Analysis, User's Manual Release 8.1. TNO Building and Construction Research, Delft, the Netherlands, 2002.

28. Collins M. P. and Mitchell D. Prestressed Concrete Structures. Prentice Hall, Englewood Cliffs, New Jersey, 1991.

29. BENTZ E. C. Explaining the riddle of tension stiffening models for shear panel experiments. Journal of Structural Engineering, 2005, 131, No. 9, 1422-1425.

30. Karlsson I. and Elfgren L. Prestressed Box-beams Loaded in Combined Torsion, Bending and Shear. Chalmers University of Technology, Göteborg, Sweden, Report 76:10, September 1976 (in Swedish)

31. Magnusson J. Anchorage of Deformed Bars over End-supports in High-strength and Normal-strength Concrete Beams: An Experimental Study. Division of Concrete Structures, Chalmers University of Technology, Göteborg, Sweden, Report 98:7, August 1998.

32. PANG X.-B. D. Constitutive Laws of Reinforced Concrete in Shear. Dissertation, Faculty of the Department of Civil and Environmental Engineering, University of Houston, Houston, TX, USA, 1991.

33. Vecchio F. J., LaI D., Shim W. and NG J. Disturbed stress field model for reinforced concrete: validation. Journal of Structural Engineering, 2001, 127, No. 4, 350-358.

34. VECCHIO F. J. and LAI D. Crack shear-slip in reinforced concrete elements. Journal of Advanced Concrete Technology, 2004, 2, No. 3, 289-300.

Discussion contributions on this paper should reach the editor by 1 May 2008 